\title{
Mental Fatigue and Its Associated Factors among Coal Mining Workers after One Year of the COVID-19 Pandemic in Indonesia
}

\author{
Hendra Djamalus $^{1 *}$, Budi Utomo², I Made Djaja ${ }^{3}$, Sjahrul M Nasri1 ${ }^{1}$
}

\begin{abstract}
${ }^{1}$ Department of Occupational Health and Safety, Faculty of Public Health, Universitas Indonesia, Depok, Indonesia, ${ }^{2}$ Department of Biostatistics and Population Studies, Faculty of Public Health, Universitas Indonesia, Depok, Indonesia, ${ }^{3}$ Department of Environmental Health, Faculty of Public Health, Universitas Indonesia, Depok, Indonesia
\end{abstract}

\begin{abstract}
Mental fatigue among coal mining operators was related to driving activities that require high concentration. This study aimed to determine factors that contributed to mental fatigue among coal mine operators in Indonesia, specifically in Kalimantan and Sumatra, after a one-year COVID-19 pandemic. This crosssectional study was conducted among 480 operators from two companies and seven sites. A self-administrated questionnaire in the Google Form was used to measure mental fatigue, the non-work-related factors (age, education, marital status, residence, and stress level), and work-related factors (working periods, shift pattern, type of shift, and work area in mining). The data analyzed using Chi-square and binomial logistic regression showed that the prevalence of mental fatigue was $32.3 \%$. Operators with moderate stress and working in the pit area demonstrated a significant association with mental fatigue ( $p$-value<0.001). Multivariable analysis showed that medium stress ( $\mathrm{AOR}=2.11 ; 95 \% \mathrm{Cl}=1.41-3.15)$ and working in the pit $(\mathrm{AOR}=2.27 ; 95 \% \mathrm{Cl}$ : $1.45-3.57)$ had a positive association with mental fatigue. Thus, the pit condition and stress levels were the dominant factors influencing mental fatigue and became points to manage mental fatigue in coal mining operators in Kalimantan and Sumatra.
\end{abstract}

Keywords: coal mining operator, COVID-19 pandemic, mental fatigue, stress

\section{Introduction}

Work-related fatigue is a common problem that has raised complaints from the working population. More than $20 \%$ of workers in the United States (US) experience fatigue every day, ${ }^{1}$ several surveys about fatigue among workers have obtained prevalence rates ranging from $7 \%$ to $45 \%$, depending on the method, instrument, and cutoff points used. ${ }^{2}$ Work fatigue for coal mining workers, especially operators, is an essential issue in occupational health and safety that needs to be managed. Operator or driver is a worker who has the main task to operate mining equipment and mining vehicles and generally works under a shift work system. Generally, operator fatigue is related to the driving activity that is more mentally than physically because it requires the coordination of sustained vigilance, selective attention, complex decision-making, and the occasional use of automatic perceptual-motor control skills. ${ }^{3}$

The characteristics of driving activities and several factors of the mining environment provide a high cognitive load to cause mental fatigue to the operator. Highlevel theories related to fatigue in mining workers include situational awareness, decreased mental resources, worker stress, and other health factors. ${ }^{4}$ In other words, the characteristics of fatigue experienced by operators are more mental fatigue. It is known that operator fatigue can cause work accidents in mining activities. Drive fatigue is one of the critical features that cause traffic accidents in mining operations. ${ }^{5}$ In open-pit mines, fatiguerelated accidents account for up to $65 \%$ of truck driving accidents alone. ${ }^{6}$ Driver fatigue causes more than $15 \%$ of fatal accidents, and nearly $20 \%$ of serious accidents are caused by driving fatigue. 7,8 Meanwhile, according to European Road Safety Observatory (ERSO), in 2018, $10 \%-25 \%$ of road accidents were caused by driver fatigue. ${ }^{9}$

Fatigue among operators is caused by both multi factors included work-related and non-work-related.10-12 Some experts stated that the main causes of operator fatigue are sleep-related issues, such as lack of sleep, poor sleep quality, and demands for sleep caused by circadian rhythms. ${ }^{4,9}$ Some causes of fatigue can be purely due to continuous high mental or cognitive activity, known as mental fatigue. Mental fatigue is related to a decrease in

Correspondence*: Hendra Djamalus, Department of Occupational Health and Safety, Faculty of Public Health, Universitas Indonesia, C Building 1st Floor Kampus Baru UI, Depok, 16424, Indonesia, E-mail: dahen@ui.ac.id, Phone: +62-21-78849033, Mobile: +628136072 2587 
motivation; the ability to process and respond to information. Mainly is the decline of incompetence, productivity, and ability to avoid mistakes or errors. ${ }^{1}$ Furthermore, working under a shift system also increases the potential to cause a decrease in a person's mental condition. Continuous mining activities that last 24 hours per day and seven days per week can cause circadian rhythm disturbances, resulting in worker fatigue, especially mental conditions. ${ }^{6}$ The high mental demand of tasks in coal mining can increase the stress level among operators. Stress also plays a vital role in the fatigue experienced and is associated with sleep problems, with higher levels of stress positively associated with fatigue. ${ }^{13,14}$

During the coronavirus disease 2019 (COVID-19) pandemic in Indonesia, which was started when the first case was discovered in March 2020 and is still ongoing, many sectors have been affected. The COVID-19 pandemic affects the health aspect and affects the business world, including coal mining. Several coal mining companies have implemented the COVID-19 prevention policies in line with local and national government policies. This condition is suspected to increase pressure on mining workers, especially operators, the largest group of workers in coal mining. This study aimed to determine non-work-related factors and work-related factors that were contribute to mental fatigue among coal mine operators in Kalimantan and Sumatra after one year of the COVID-19 pandemic in Indonesia.

\section{Method}

This cross-sectional study was conducted one year after the COVID-19 pandemic in Indonesia, where data collection started from mid-March to mid-April 2021. The study involved two coal mining companies, seven mining sites, and 480 operators. The sample was calculated using simple random sampling formula (CI: $95 \%$, $d=5 \%$, p-value $=0.57$ ), and a minimum sample of 379 was determined based on a previous study. ${ }^{15}$ The sampling technique used was simple random sampling. Participants were recruited based on a list of employees who were on shift during the data collection period. Data was collected using a self-administered questionnaire based on a Google Form and filled out online regarding government and company's pandemic policies.

The participants received a link address to answer the questionnaire on their smartphones. All participants gave written informed consent by selecting the (yes) button in the online questionnaire for the question: "Are you willing to be a respondent for this research?" The participants were instructed to fill out the questionnaire at the off time, shift change break, or at the end of the daily shift while resting in the company mess or at home after a minimum of four days of work. The questionnaire in- cluded questions about mental fatigue, non-work-related factors (age, education, marital status, residence, and stress level), and work-related factors (working periods, shift pattern, type of shift, and work area in mining).

Mental fatigue was measured using the selected items from three standard questionnaires. The first questionnaire is the Checklist of Individual Strength-20 (CIS-20), which measures mental fatigue on items $3,8,11,13$, and 19. ${ }^{16}$ The second questionnaire is the Multidimensional Fatigue Inventory-20 (MFI) that measures mental fatigue on items $7,11,13$, and 19.17 The third questionnaire is Swedish Occupational Fatigue Inventory (SOFI) and measures mental fatigue on items 5, 9, 14, and 16.18 All three questionnaires used a Likert scale. The CIS-20 has a score from 1 to 7 , MFI has a score from 1 to 5 , and SOFI has a score from 0 to 6 . The participants were categorized into experiencing mental fatigue on each questionnaire if they had a total score exceeding the median value. The three instruments used to measure mental fatigue must indicate mental fatigue, and then a participant would be categorized as experienced mental fatigue.

The questions about non-work-related factors, including age (30-44 years/ $<30$ years and $\geq 45$ years), education (junior high school or less/senior high school or more), marital status (single or divorced/married), and stress level that measured using 10 items of Perceived Stress Scale by Cohen. ${ }^{19-21}$ The questions about workrelated factors, including working periods $(<10$ years or $\geq 10$ years), shift pattern (8-hours shift/12-hours shift), type of shift (day shift/night shift), and location of work in mining (hauling area/pit area). Association between non-work-related factors and work-related factors with mental fatigue was analyzed by Chi-square test or Fisher exact test as per applicability, p-value $<0.05$ was considered as significant at a $95 \%$ confidence interval (CI). Variables that had a p-value $<0.25$ were considered for multivariate binomial logistic regression.

\section{Results}

The total of operators who completed the online selfadministered questionnaire was 480 . The prevalence of mental fatigue was $32.3 \%$ based on the criteria in the total sample. Operators were determined to experience mental fatigue when all the questionnaires had the same result as mental fatigue. This study only measured the prevalence of mental fatigue on operators without differentiating its level.

This study measured five variables related to nonwork factors: age, education, marital status, place of residence, and stress level. The average age was $32( \pm 6)$ years, with a range of 21-58 years old. Table 1 shows the non-work-related factors of the study participants or operators. Most coal mining operators were married $(85 \%)$ and living at home $(63.5 \%)$. They have a relatively good 
level of education, which most of them (97.9\%) graduated from senior high school or college/university. The highest stress level among operators was moderate, with a percentage almost similar to operators with low stress $(49.4 \%$ compared to $50.6 \%)$. The Chi-square test showed only stress levels in the non-work-related factors that indicated a significant association with mental fatigue ( $\mathrm{p}$-value $<0.001$ ).

The work-related factors in this study are shown in Table 2. Most of the operators $(60.2 \%)$ had $\geq 10$ years of working periods as an operator. The majority $(65.8 \%)$ of operators worked in the pit area. The pit area is the central location of the coal mining activities requiring various tasks and equipment involved during the mining process. The number of operators according to day shift and night shift was approximately equal, so there was no significant difference in the percentage of mental fatigue between day and night shifts.

The work-related factor that demonstrated a significant association with mental fatigue was work location in mining. Operators who worked in the pit area (38.6\%) experienced more mental fatigue than those in the hauling area $(20.1 \%)$. Mental fatigue more occurrence among operators with $\geq 10$ years of working periods $(34.9 \%)$ compared to operators with $<10$ years of working periods $(28.3 \%)$, as same as working with 8-hours shift pattern (34.2\%) compared to 12-hours shift pattern $(30.4 \%)$.

Multivariate analysis with a binomial logistic regression test was used to determine contributing factors of mental fatigue among coal mining operators. Table 3 shows the results of the multivariable analysis. Four variables have met the criteria as candidates of multivariate analysis ( $p$-value $<0.25$ ). The four variables include age, years of service, stress level, and working location in mining from Table 1 and 2. The results of the analysis showed that age and working period were excluded from the multivariable model.

The result of the multivariable analysis shows that the work area in mining had more contributed to mental fatigue than the stress level. Working in the pit area was more likely to experience mental fatigue $(\mathrm{AOR}=2.27$;

Table 1. Non-work-related Factors and Their Association with Mental Fatigue $(n=480)$

\begin{tabular}{|c|c|c|c|c|c|}
\hline \multirow{3}{*}{ Variable } & \multirow{3}{*}{ Category } & \multicolumn{3}{|c|}{ Mental Fatigue } & \multirow{3}{*}{ p-value } \\
\hline & & Total & Yes & No & \\
\hline & & n $(\%)$ & n $(\%)$ & n $(\%)$ & \\
\hline \multirow[t]{2}{*}{ Age (year) } & $30-44^{a}$ & $267(55.6)$ & $96(36.0)$ & $171(64.0)$ & 0.07 \\
\hline & $<30$ and $\geq 45$ & $213(44.4)$ & $59(27.7)$ & $154(72.3)$ & \\
\hline \multirow[t]{2}{*}{ Education } & Senior high school or morea & $470(97.9)$ & $152(32.2)$ & $318(67.7)$ & 1.00 \\
\hline & Junior high school or less & $10(2.1)$ & $3(30.0)$ & $7(70.0)$ & \\
\hline \multirow[t]{2}{*}{ Marital status } & Single or divorced ${ }^{\mathrm{a}}$ & $72(15.0)$ & $24(33.3)$ & $48(66.7)$ & 0.95 \\
\hline & Married & $408(85.0)$ & $131(32.1)$ & $277(67.9)$ & \\
\hline \multirow[t]{2}{*}{ Place of residence } & Company mess ${ }^{a}$ & $175(36.5)$ & $54(30.9)$ & $12(69.1)$ & 0.68 \\
\hline & Home & $305(63.5)$ & $101(33.1)$ & $204(66.9)$ & \\
\hline \multirow[t]{2}{*}{ Stress level } & Low $^{\mathrm{a}}$ & $243(50.6)$ & $57(23.5)$ & $186(76.5)$ & $<0.001 *$ \\
\hline & Moderate & $237(49.4)$ & $98(41.4)$ & $139(58.6)$ & \\
\hline
\end{tabular}

Notes: *Indicates significance at p-value $<0.05$, aReference category

Table 2. Work-related Variables and Their Association with Mental Fatigue $(n=480)$

\begin{tabular}{|c|c|c|c|c|c|}
\hline \multirow{3}{*}{ Variable } & \multirow{3}{*}{ Category } & \multicolumn{3}{|c|}{ Mental Fatigue } & \multirow{3}{*}{ p-value } \\
\hline & & Total & Yes & No & \\
\hline & & n (\%) & n (\%) & n (\%) & \\
\hline \multirow[t]{2}{*}{ Working periods (year) } & $<10^{a}$ & $191(39.8)$ & $54(28.3)$ & $137(71.7)$ & \multirow[t]{2}{*}{0.15} \\
\hline & $\geq 10$ & $289(60.2)$ & $101(34.9)$ & $188(65.1)$ & \\
\hline \multirow[t]{2}{*}{ Shift pattern } & $3\left(^{(8 \text { hours })^{\mathrm{a}}}\right.$ & $240(50.0)$ & $82(34.2)$ & $158(65.8)$ & \multirow[t]{2}{*}{0.44} \\
\hline & 2 (12 hours) & $240(50.0)$ & $73(30.4)$ & $167(69.6)$ & \\
\hline \multirow[t]{2}{*}{ Shift type } & Day shift ${ }^{\mathrm{a}}$ & $240(50.0)$ & $77(32.1)$ & 163 (67.9) & \multirow[t]{2}{*}{1.00} \\
\hline & Night shift & $240(50.0)$ & $78(32.5)$ & $162(67.5)$ & \\
\hline \multirow[t]{2}{*}{ Work area in mining } & Hauling area ${ }^{\mathrm{a}}$ & $164(34.2)$ & $33(20.1)$ & 131 (79.9) & \multirow[t]{2}{*}{$<0.001$} \\
\hline & Pit area & $316(65.8)$ & $122(38.6)$ & $194(61.4)$ & \\
\hline
\end{tabular}

Notes: *Indicates significance at p-value $<0.05$, aReference category 
Table 3. Multivariable Analysis Factors Contributed to Mental Fatigue

\begin{tabular}{|c|c|c|c|c|c|}
\hline \multirow{2}{*}{ Variable } & \multirow{2}{*}{$\beta$} & \multirow{2}{*}{ Sig. } & \multirow{2}{*}{$\operatorname{Exp}(B)$} & \multicolumn{2}{|c|}{ 95\% CI for $\operatorname{Exp}(\mathrm{B})$} \\
\hline & & & & Lower & Upper \\
\hline Work area in mining & 0.821 & .000 & 2.272 & 1.447 & 3.567 \\
\hline Stress level & 0.746 & .000 & 2.108 & 1.412 & 3.146 \\
\hline Constant & -1.709 & .000 & 0.181 & & \\
\hline
\end{tabular}

Note: CI: Confidence Interval

95\% CI $=1.45-3.57)$ in operators than in the hauling area. At the same time, operators with moderate stress levels were more likely to experience mental fatigue than operators with a low level of stress (AOR $=2.11$; $95 \%$ $\mathrm{CI}=1.41-3.15)$. The multivariable analysis was conducted by controlling by working period and age as covariates.

\section{Discussion}

Mental fatigue in coal mining operators is closely related to the characteristics of driving work. Operators whose main job is to operate mining equipment or vehicles are particularly vulnerable to mental fatigue. This study found that the prevalence of operators who experienced mental fatigue was $32.3 \%$. This percentage is still in the range of the fatigue prevalence among workers, which is $7 \%-45 \% .^{2}$ This study result indicated that the percentage of operator experienced mental fatigue was lower than the study on drivers in Spain found 38.5\% of drivers experienced mental fatigue. That study found a high proportion of drivers frequently drove under the condition that causes cognitive, emotional, and motor deterioration, thus affecting driving. ${ }^{22}$ Another study of fatigue and its associated risk factors among electronics manufacturing shift workers in Malaysia also found that $30.2 \%$ of the workers have experienced mental fatigue. ${ }^{23}$ The high percentage of mental fatigue among coal mining operators indicated that mental fatigue was a critical issue in coal mining companies and needed control measures. The mental fatigue among the operator was related to various factors such as characteristics of the driving task. Operators must be stay alert during the working time because they are usually driving alone on a lonely road or driving in a crowded area in the pit.

This study examined the contributing factors of mental fatigue from non-work-related and work-related factors. Based on the literature, respondents categorized in the risk group (exposed) are aged $<30$ years and $\geq 45$ years, have low education, are married, live at home, and have high stress. ${ }^{13,19,20,23,24}$ The analysis showed that only stress levels as non-work-related factors that are significantly associated with mental fatigue. The results showed that $41.4 \%$ of operators who experience moder- ate stress levels experienced mental fatigue. Fatigue was also positively associated with higher levels of stress. ${ }^{16}$ Uncontrolled and chronic stress is one of the main factors causing fatigue, ${ }^{26}$ or fatigue is one of the implications of chronic stress from continuous physical and cognitive work. ${ }^{27}$

Driving a mining vehicle is one task that requires high cognitive effort and must maintain concentration for a long time. ${ }^{3}$ Study on 213 male workers in the manufacturing industry in Japan found that psychological stress correlates with fatigue, ${ }^{28}$ and decreased performance. ${ }^{3}$ Operators with a high-stress level are more likely to experience mental fatigue than those with lower stress levels $(O R=2.11)$. Higher stress level is significantly associated with mental fatigue. Driver stress contributes not only to fatigue but also to decrement in driver performance.

Stress among coal mining operators can increase due to conditions such as time pressure to complete a job, long work hours, monotonous driving, personal situations, communication in the mining area, unpredictable and hazardous road conditions, and other truck traffic. ${ }^{3}$ Stress and mental fatigue can be two things that affect each other. Operators who experience stress due to work demands and other factors will be more prone to experiencing mental fatigue. On the other hand, operators who experienced mental fatigue due to work pressure and personal characteristics are more likely to get stress acutely and long. Therefore, stress management programs are most important in reducing the occurrence of mental fatigue.

Another determinant factor of mental fatigue among coal mining operators in Kalimantan and Sumatra is working in the pit area. This study divided the working area into the pit area and hauling area. The work environment or work area is one of the main causes of fatigue in mining workers. ${ }^{25}$ The results showed that operator who work in the pit area has the possibility of experiencing mental fatigue 2.3 times higher than operators who worked in the hauling area. A study in China on the effect of fatigue on driving performance found that the effects of fatigued driving were higher on curved, downhill, and changing directions than straight roads. ${ }^{9}$ The result of this study indicated that the pit area of mining which has many curves and intersections, road geometry conditions, and traffic lanes that often change, caused more fatigue than straight lines like in the hauling area. The pit area is the central area of coal mining activities. The situation in the pit area can create a stressful work environment. In surface mining, the condition of the pit area is very dynamic and usually changes according to the progress of the mining work. Changing the mine road and intersections, traffic, mine design, and layout, and also changes the pit topography caused by climate conditions are some 
examples in the pit area that contributed to mental fatigue. 3,11

The mining design is an essential first step of the coal mining process. The implementation of excellence and proper mining design that complies with mining safety standards and at the same time also fulfills the occupational health and safety standards are essential approaches to develop control measures to reduce mental fatigue. A holistic approach to managing the mental fatigue among coal mining operators should consider various aspects, such as work-time arrangements, work design, environmental factors, and personal factors. ${ }^{11}$

This study has several limitations. The first is using online self-administered questionnaires. Regarding the pandemic policy, visiting the study sites were not allowed. Coordination with safety personnel and managements personnel was conducted to distribute the link address of the questionnaire and explain the study objective to the respondents. Another limitation in this study is using a cross-sectional design that will not allow the authors to conclude causality for the established associations. In addition, future researchers may benefit from this research by investigating other factors that contribute to mental fatigue, such as the social life of coal mining operators, management programs related to fatigue management, and so forth. The future study design should be quantitative and qualitative. This study will help to understand mental fatigue from both non-workrelated and work-related perspectives, and determine factors that become entry points for intervention programs.

\section{Conclusion}

Working in the coal pit area and the stress level on the operator are two factors that significantly contribute to the mental fatigue experienced by coal mining operators in Kalimantan and Sumatra, especially concerning after one year of the COVID-19 pandemic in Indonesia. The non-work-related factor that had a significant relationship with mental fatigue was moderate stress levels. While on work-related factors, working in the pit area is a factor that has a significant association with mental fatigue. The two factors have almost the same odds ratio to caused mental fatigue. The coal mining company can develop programs to deal with mental fatigue by creating programs to minimize worker stress and design the mining area that complies with related standards and regulations.

\footnotetext{
Abbreviations

US: United States; ERSO: European Road Safety Observatory; COVID19: coronavirus disease 2019; CIS-20: Checklist of Individual Strength20; MFI: Multidimensional Fatigue Inventory-20; SOFI: Swedish Occupational Fatigue Inventory; CI: Confidence Interval; AOR: Adjusted Odd Ratio.
}

\section{Ethics Approval and Consent to Participate}

This study was approved by the Ethical Committee of the Faculty of Public Health, Universitas Indonesia, under the ethical clearance number: Ket-28/UN2.F10.D11/PPM.00.02/2021. Informed consent was obtained from all participants before filling the questionnaires.

\section{Competing Interest}

The authors declare that there are no significant competing financial, professional, or personal interests that might have affected the performance or presentation of the work described in this manuscript.

\section{Availability of Data and Materials}

Data and information used as study materials were original study conducted by the corresponding author.

\section{Authors' Contribution}

HD conceptualized, designed, and prepared the manuscript. BU, IMD, and SMN, as the counsel in conducted study, developed the analytical framework of data.

\section{Acknowledgment}

This study was supported by HSE personnel in the mining sites located in Kalimantan and Sumatra and the management personnel of both companies. The authors thank both companies for the permission in conducting the study, Abdul Kadir, S.KM, M.Sc., for proofreading the draft of manuscript, and Indri Hapsari Susilowati, S.KM, M.KKK, $\mathrm{Ph} . \mathrm{D}$., for helping in the process of submitting the manuscript.

\section{References}

1. Techera U, Hallowell M, Stambaugh N, Littlejohn R. Causes and consequences of occupational fatigue: meta-analysis and systems model. Journal of Occupational and Environmental Medicine. 2016; 58 (10): 961-73.

2. Yazdi Z, Sadeghniiat-Haghighi K. Fatigue management in the workplace. The Industrial Psychiatry Journal. 2015; 24 (1): 12.

3. Eiter BM, Steiner L, Kelhart A. Application of fatigue management systems: small minesand low technology solutions application of fatigue. Minerals Engineering. 2014; 66 (4): 69-75.

4. Bauerle T, Dugdale Z, Poplin G. Mineworker fatigue: a review of what we know and future decisions. Minerals Engineering. 2018; 70 (3): 119.

5. Sun E, Nieto A, Li Q. The drive fatigue pattern monitor for haul truck drivers in surface mining operations. In: 2015 12th International Conference on Fuzzy Systems and Knowledge Discovery, FSKD 2015. 2016 p. $1329-34$

6. Martell M. Mine worker fatigue and circadian rhythms. Coal Age. 2018; 123 (4): 38-40.

7. Perttula P, Ojala T, Kuosma E. Factors in the fatigue of heavy vehicle drivers. Psychological Reports. 2011; 108 (2): 507-14.

8. Jiang K, Ling F, Feng Z, Wang K, Shao C. Why do drivers continue driving while fatigued? An application of the theory of planned behaviour. Transportation Research Part A: Policy and Practice. 2017; 98: $141-9$. 
9. European Road Safety Observatory (ERSO). Fatigue 2018; 2018.

10. Chan APC, Song W, Yang Y. Meta-analysis of the effects of microclimate cooling systems on human performance under thermal stressful environments: potential applications to occupational workers. Journal of Thermal Biology. 2015; 49-50: 16-32.

11. Theron WJ, van Heerden GMJ. Fatigue knowledge: a new lever in safety management. Journal of the Southern African Institute of Mining and Metallurgy. 2011; 111: 1-10.

12. Rail Safety and Standards Board Limited. Driving for work: managing fatigue risks a guide for road vehicle drivers and their managers. RSSB. 2013 p. 28.

13. Åkerstedt T, Axelsson J, Lekander M, Orsini N, Kecklund G. Do sleep, stress, and illness explain daily variations in fatigue? A prospective study. Journal of Psychosomatic Research. 2014; 76 (4): 280-5.

14. Pelders JL. Tired of socio-economic stress : socio-demographic contributors to fatigue of mine workers in South Africa. University of the Witwatersrand, Johannesburg; 2020.

15. Pelders J, Nelson G. Contributors to fatigue of mine workers in the South African Gold and Platinum Sector. Safety and Health at Work. 2019; 10 (2): 188-95.

16. Worm-Smeitink M, Gielissen M, Bloot L, van Laarhoven HWM, van Engelen BGM, van Riel P, et al. The assessment of fatigue: psychometric qualities and norms for the checklist individual strength. Journal of Psychosomatic Research. 2017; 98: 40-6.

17. Azmeh Shahid, Wilkinson K, Marcu S, Shapiro CM, editors. Multidimentional fatigue inventory. In: STOP, THAT and One Hundred Other Sleep Scales. Springer. 2012 p. 241-3.

18. Sagherian K, Geiger-Brown J. In-depth review of five fatigue measures in shift workers. Fatigue: Biomedicine, Health \& Behavior. 2016; 4 (1): 24-38.

19. Di Milia L, Smolensky MH, Costa G, Howarth HD, Ohayon MM, Philip P. Demographic factors, fatigue, and driving accidents: an ex- amination of the published literature. Accident Analysis \& Prevention. 2011; 43 (2): 516-32.

20. Fletcher A. Staying safe in the jungles of Borneo: five studies of fatigue and cultural issues in remote mining projects. Industrial Health. 2010; 48 (4): 406-15.

21. New Hampshire D of AS (DAS). Perceived stress scale score cut off. State of New Hampshire Employee Assistance Program. 2014 p. 2.

22. Alonso F, Esteban C, Useche SA, López De Cózar E. Prevalence of physical and mental fatigue symptoms on spanish drivers and its incidence on driving safety. Advances in Psychology and Neuroscience. 2016; 1 (2): 10-8.

23. Phillips RO, Sagberg F. Managing driver fatigue in occupational settings. Oslo; 2010.

24. Aazami S, Mozafari M, Shamsuddin K, Akmal S. Work-family conflict and sleep disturbance: the Malaysian working women study. Industrial Health. 2016; 54: 50-7.

25. Hanifah MSA, Ismail N. Fatigue and its associated risk factors: a survey of electronics manufacturing shift workers in Malaysia. Fatigue: Biomedicine, Health \& Behavior. 2020; 8 (1): 49-59.

26. Kop WJ, Kupper N. Fatigue and stress. In Fink G, editor, Stress: Concepts, cognition, emotion, and behavior. Academic Press. 2016 p. 345-50.

27. Hancock PA, Desmond PA, Matthews G. Conceptualizing and defining fatigue. In: Matthews G, Desmond PA, Neubauer C, Hancock PA, editors. The Handbook of Operator Fatigue. Surrey: Ashgate Publishing Limited. 2012 p. 63-74.

28. Nishitani N, Sakakibara H. Association of psychological stress response of fatigue with white blood cell count in male daytime workers. Industrial Health. 2014; 52 (6): 531-4. 